\title{
Article \\ Mathematical Modeling of Lactobacillus paracasei CBA L74 Growth during Rice Flour Fermentation Performed with and without $\mathrm{pH}$ Control
}

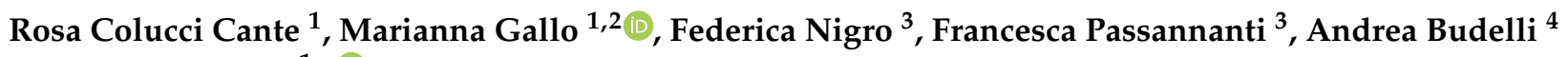 \\ and Roberto Nigro ${ }^{1, *(1)}$ \\ 1 Department of Chemical Engineering, Material and Industrial Production, University of Naples Federico II, \\ P. Tecchio 80, 80125 Naples, Italy; rosa.coluccicante@unina.it (R.C.C.); marianna.gallo@unina.it (M.G.) \\ 2 Department of Industrial Engineering, University of Niccolò Cusano, Via Don Carlo Gnocchi 3, \\ 00166 Rome, Italy \\ 3 I. T. P. Innovation and Technology Provider S.r.l. Via Bisignano a Chiaia 68, 80121 Naples, Italy; \\ federicanigro@itpna.it (F.N.); francesca.passannanti@itpna.it (F.P.) \\ 4 Heinz Innovation Center, Nieuwe Dukenburgseweg 19, 6534 AD Nijmegen Postbus 57, \\ NL-6500 AB Nijmegen, The Netherlands; Andrea.Budelli@kraftheinz.com \\ * Correspondence: rnigro@unina.it; Tel.: +39-081-7682249
}

check for updates

Citation: Colucci Cante, R.; Gallo, M.; Nigro, F.; Passannanti, F.; Budelli, A.; Nigro, R. Mathematical Modeling of Lactobacillus paracasei CBA L74 Growth during Rice Flour Fermentation Performed with and without pH Control. Appl. Sci. 2021, 11, 2921. https://doi.org/10.3390/ app11072921

Academic Editor: Ramona Iseppi

Received: 15 February 2021

Accepted: 21 March 2021

Published: 25 March 2021

Publisher's Note: MDPI stays neutral with regard to jurisdictional claims in published maps and institutional affiliations.

Copyright: (c) 2021 by the authors. Licensee MDPI, Basel, Switzerland. This article is an open access article distributed under the terms and conditions of the Creative Commons Attribution (CC BY) license (https:// creativecommons.org/licenses/by/ $4.0 /)$.

\begin{abstract}
The mathematical modeling of fermentation processes allows for the formulation of predictions about the kinetics of biomass growth and metabolite production as well as setting or verifying the best operative conditions in view of the economical convenience of the process. For this purpose, we performed a kinetic study of a rice flour fermentation process using Lactobacillus paracasei CBA L74 with and without $\mathrm{pH}$ control; the $\mathrm{pH}$ value was set to 5.8 under $\mathrm{pH}$ control. Monod, Logistic, and Contois models were proposed to describe the bacterial growth rate in both conditions. The best mathematical model, which was able to describe the experimental data obtained without $\mathrm{pH}$ control, was the Contois model, as the specific growth rate was influenced by both the glucose reduction (from $14.31 \mathrm{~g} / \mathrm{L}$ to $10.22 \mathrm{~g} / \mathrm{L}$ ) and the biomass production (2 log growth) that occurred during fermentation. Conversely, when $\mathrm{pH}$ control was implemented, both Monod and Contois models satisfactorily described the specific growth rate trend. The estimated kinetic parameters confirmed that biomass production (2 log growth) and glucose consumption (from $14.31 \mathrm{~g} / \mathrm{L}$ to $6.06 \mathrm{~g} / \mathrm{L}$ ) did not affect the microorganism's growth capacity when the fermenting medium was maintained at an optimal $\mathrm{pH}$. The lactic acid production rate described by the Luedeking-Piret model did not appear to be linked to growth in the absence of $\mathrm{pH}$ control while, on the other hand, this model was unsuitable for describing the experimental lactic acid concentration when $\mathrm{pH}$ control was applied. The kinetic modeling of lactic acid production and the percentage of added glucose in the protocol with controlled $\mathrm{pH}$ will be optimized in the future.
\end{abstract}

Keywords: kinetic modeling; pH control; rice flour fermentation; specific growth rate; lactic acid production rate; biokinetic parameters

\section{Introduction}

There is increasing scientific evidence regarding the concept of food not only as a source of energy and vehicle of essential nutrients for the body, but also as an instrument that is able to beneficially influence some biological functions and reduce the risk of disease development [1].

In recent years, the scientific research on functional foods has mainly focused on the identification of biologically active components in foods that have the potential to provide specific beneficial effects for human health and reduce the risk of diseases.

Several techniques were developed in order to enhance the content of these bioactive compounds or promote their production in food products. Lactic acid fermentation is one 
of the most important food processing technologies used to produce functional probiotic foods. Currently, most probiotics available on the market are dairy based, consisting of several types of fermented milks, yogurts, and cheeses [2]. The choice of different fermenting substrates, such as cereals, fruits, vegetables, and legumes, as alternatives to dairy-based foods, is one way to meet the needs of consumers affected by lactose intolerance, milk protein allergy, high blood cholesterol content, or requiring a low-fat $\operatorname{diet}[3]$.

The fermenting strain used for this work was Lactobacillus paracasei (LP) CBA L74, and its probiotic nature was already demonstrated by in vivo studies [4]. Fermentation of cerealbased substrates using LP CBA L74 as a starter culture was widely studied in previous works for aqueous rice, oat, and wheat flour suspensions [5,6], and for aqueous mixtures of oat and rice flours [7], highlighting how the addition of different concentrations of glucose to the fermenting medium could affect bacterial growth and lactic acid production during the process.

Moreover, the microbial activity of LP CBA L74 was also investigated for legumebased substrates [8] and for minimal fermenting broths as a rice flour supernatant [9].

The functional ability of cereals fermented with LP CBA L74 was demonstrated by in vitro studies reported by Sarno et al. [10] and Gallo et al. [11], where the effect of inhibiting gliadin peptide P31-43 entry into the epithelial cells of fermented rice was studied in order to propose an alternative therapeutic approach to the gluten-free diet for celiac patients. Moreover, the experimental results showed that the inhibiting effect was evidently improved when $\mathrm{pH}$ control was applied during the process [11]. It is important to establish the optimal operating conditions for fermentation, which would be beneficial not only in terms of improving the functional effect of fermented products on consumer health, but also from an economic point of view, in terms of improved production.

For this reason, knowledge of the fermentation process kinetics through the development of mathematical models plays a vital role in designing and developing improved strategies for optimization and in controlling and scaling up biological process systems to ensure their economic viability $[12,13]$.

For this purpose, kinetic modeling for Lactobacillus helveticus, Lactobacillus casei, Lactobacillus delbrueckii, Lactobacillus fermentum, and Lactobacillus bulgaricus growth and acid production has been reported by several researchers [14-19]. To describe a microbial process, two kinds of models can be developed, structured and unstructured models. Structured models take into account cell structure, their function, and composition.

Although they have been reported to accurately describe lactic acid fermentation [16,20], they are very complex. In unstructured models, only total cellular concentration is considered, and hence, no physiological characterization of the cells is needed.

The simplest non-structural growth model was proposed by Jacques Monod in 1942, who described the bacterial growth rate based on the limiting substrate concentration during the fermentation process [21]. The Monod model is not able to predict possible inhibition effects by high substrate content, produced metabolites, and the increasing biomass density; thus, different models are used to overcome the limitations of the Monod equation in describing more complex systems, such as Contois, Logistic, Haldane, Moser, Tessier, and Powell models [22]. The aim of the present work was to perform a kinetic analysis of the results reported by Gallo et al. [11] for rice flour fermentation performed using Lactobacillus paracasei CBA L74 with and without $\mathrm{pH}$ control. Gallo et al. [5] had already demonstrated the possibility of improving the functional properties of the fermented rice product by controlling the $\mathrm{pH}$ at 5.8 , but a comparison between the kinetic performances, corresponding to the two different process conditions, had not been conducted yet.

Three unsegregated and unstructured kinetic models were proposed to describe the rice flour fermentation process. In particular, the Monod, Logistic, and Contois models were chosen to investigate the effect of the limiting substrate consumption (glucose), biomass formation, and both biomass and substrate concentrations, respectively, on the cell growth rate during the fermentation process, carried out with and without $\mathrm{pH}$ control. 
Therefore, the biokinetic parameters for each model proposed were estimated and the effect of $\mathrm{pH}$ control on the microorganism's kinetic behavior during the process was evaluated.

\section{Materials and Methods}

\subsection{Strain and Feedstock}

The strain used as the starter culture was Lactobacillus paracasei CBA L74, patented and provided by Heinz Italia S.p.A (Latina, Italy; International Depository Accession Number LMG P-24778).

It was stored at $-20{ }^{\circ} \mathrm{C}$ in cryovials with glycerol $(20 \%)$ to preserve its viability during a maximum storage period of four weeks and was revitalized in $10 \mathrm{~mL}$ of an animal-free broth (20 g/L Bacto Yeast Extract, BD Biosciences, Milan, Italy; $0.5 \mathrm{~g} / \mathrm{L} \mathrm{MgSO}_{4}$, SigmaAldrich, Milan, Italy; $50 \mathrm{~g} / \mathrm{L}$ glucose, Sigma-Aldrich; $0.5 \mathrm{~g} / \mathrm{L}$ citric acid, Sigma-Aldrich) by incubation at $37^{\circ} \mathrm{C}$ for $24 \mathrm{~h}$ before inoculation. The cell density in the inoculum broth was $10^{8} \mathrm{CFU} / \mathrm{mL}$. Rice flour was provided by Heinz Italia S.p.A, Latina, Italy.

\subsection{Experimental Apparatus}

Fermentation tests were carried out using the same experimental laboratory system described by Gallo et al. [5,11]. Briefly, the system consisted of a batch reactor $(20 \mathrm{~cm}$ high, $10 \mathrm{~cm} \mathrm{ID}, 1.5 \mathrm{~L}$ ) equipped with an external jacket for the circulation of a service fluid coming from a thermostatically controlled water bath. The mixing system was a stainless-steel impeller consisting of an inclined blade turbine and a Rushton turbine. The impeller was equipped with an input for the insertion of the In Pro 3100 probe (Mettler Toledo, Milan, Italy), connected to the M300 transmitter (Mettler Toledo, Milan, Italy), which is useful for inline temperature $/ \mathrm{pH}$ measurements, and an input connected to a tank containing a $0.2 \mathrm{M} \mathrm{NaOH}$ solution, fed by a peristaltic pump used for $\mathrm{pH}$ control.

\subsection{Fermentation Protocol}

The fermentation tests were carried out according to the protocol reported by Gallo et al. [11] with some modifications. Briefly, $1 \mathrm{~L}$ of a rice flour suspension $(15 \% w / v)$ in water with $1 \% w / v$ of added glucose was loaded in the reactor. Enzymatic pretreatment of the rice suspension using amylase $(0.012 \% \mathrm{w} / \mathrm{v})$ ) was carried out at $85^{\circ} \mathrm{C}$ for $20 \mathrm{~min}$ to prevent starch gelification and to guarantee the homogeneity of the suspension during the fermentation process.

After sterilization in an autoclave at $121^{\circ} \mathrm{C}$ for $20 \mathrm{~min}$, the system was cooled down to $37^{\circ} \mathrm{C}$ and the strain was inoculated $(1 \% v / v)$ to begin the fermentation process. Fermentation tests were performed with (set to 5.8) and without $\mathrm{pH}$ control for $24 \mathrm{~h}$ at $37^{\circ} \mathrm{C}$.

Eleven samples, consisting of $10 \mathrm{~mL}$ of fermented matrix, were withdrawn aseptically from the reactor at specific times (after the inoculum $\left(\mathrm{t}_{0}\right)$ and after $2 \mathrm{~h}\left(\mathrm{t}_{2}\right), 4 \mathrm{~h}\left(\mathrm{t}_{4}\right), 6 \mathrm{~h}\left(\mathrm{t}_{6}\right)$, $8 \mathrm{~h}\left(\mathrm{t}_{8}\right), 14 \mathrm{~h}\left(\mathrm{t}_{14}\right), 16 \mathrm{~h}\left(\mathrm{t}_{16}\right), 18 \mathrm{~h}\left(\mathrm{t}_{18}\right), 20 \mathrm{~h}\left(\mathrm{t}_{20}\right), 22 \mathrm{~h}\left(\mathrm{t}_{22}\right)$, and $24 \mathrm{~h}\left(\mathrm{t}_{24}\right)$ of fermentation) and bacterial growth, lactic acid production, glucose, and starch concentration were measured for each sample.

\subsection{Analytical Methods}

Bacterial growth was monitored by serial dilutions and the spread plate method on Petri plates filled with De Man, Rogosa, and Sharpe (MRS) agar (Oxoid, Basingstoke, UK). MacConkey agar (Oxoid, Basingstoke, UK) and Gelatin Peptone Bios Agar (Biolife, Milan, Italy) were used to control the presence of microbial contaminants (coliform and aerobic microorganisms, respectively) in the fermenting medium. All plates were incubated at $37^{\circ} \mathrm{C}$ for $48 \mathrm{~h}$ before reading.

Special anaerobic kits (Anaerogen Compact, Oxoid, Basingstoke, UK) were used for MRS plates to guarantee anaerobic growth conditions for LP CBA L74 during the incubation period. In order to determine the biomass concentration, expressed in $\mathrm{g} / \mathrm{L}$, the cell weight was estimated as described below. 
The inoculum broth, with a bacterial load of $10^{8} \mathrm{CFU} / \mathrm{mL}$ previously measured using serial dilutions and spread plate method on MRS agar, was centrifuged and the supernatant was discharged. The pellet was weighed and a specific biomass weight of $10^{-12} \mathrm{~g} / \mathrm{CFU}$ was calculated.

The amount of lactic acid produced was assessed by high-performance liquid chromatography (HPLC), Agilent 1100 series (Agilent Technologies, Milan, Italy), equipped with an Agilent Zorbax C18 column (150 $\mathrm{mm} \times 4.6 \mathrm{~mm}$ and a pore size of $8 \mu \mathrm{m})$ with a visible/UV detector. The eluent was $1 \% \mathrm{NH}_{4} \mathrm{H}_{2} \mathrm{PO}_{4}$ aqueous solution at a $\mathrm{pH}$ of 2.7, modified with $\mathrm{H}_{2} \mathrm{PO}_{4}$ with a flow rate of $0.8 \mathrm{~mL} / \mathrm{min}$.

The detection was set at $218 \mathrm{~nm}$. Moreover, the concentration of glucose was determined by HPLC, Agilent 1100 series (Agilent Technologies, Milan, Italy), with a refractometer index (RI) detector, using a Rezex RHM-Monosaccharide column $(300 \mathrm{~mm} \times 7.8 \mathrm{~mm}$ and a pore size of $8 \mu \mathrm{m}$ ). The eluent was $3.5 \mathrm{mM} \mathrm{H}_{2} \mathrm{SO}_{4}$ aqueous solution with a flow rate of $0.6 \mathrm{~mL} / \mathrm{min}$. The starch content was determined using a total starch assay kit (AA/AMG) (Megazyme) with spectrophotometric measurement at $510 \mathrm{~nm}$.

\subsection{Fermentation Parameters}

The time needed for the microorganism to double in number during the exponential growth phase, known as doubling time $\left(t_{d}\right)$, was calculated using Equation (1) [23]:

$$
\mathrm{td}=\frac{\mathrm{t}_{\mathrm{exp}}}{\mathrm{n}}
$$

where $t_{\exp }$ is the duration of the exponential phase and $n$ is the number of generations, calculated by Equation (2) [23]:

$$
\mathrm{N}_{\mathrm{f}}=\mathrm{N}_{0} \times 2^{\mathrm{n}},
$$

where $\mathrm{N}_{0}$ and $\mathrm{N}_{\mathrm{f}}$ are the numbers of cells at the beginning and at the end of the exponential growth period $t_{\text {exp }}$, respectively. The constant growth rate, $k$, is defined in Equation (3):

$$
\mathrm{k}=\frac{\mathrm{n}}{\mathrm{t}_{\mathrm{exp}}}=\frac{1}{\mathrm{t}_{\mathrm{d}}}
$$

\subsection{Kinetic Models}

The growth rate, $r_{x}$, can be expressed in terms of first order kinetics with respect to the biomass concentration according to Equation (4) [24]:

$$
\mathrm{r}_{\mathrm{x}}=\frac{\mathrm{dX}}{\mathrm{dt}}=\mu \mathrm{X}
$$

where $\mu$ is the specific growth rate $\left(\mathrm{h}^{-1}\right)$.

By applying the separation of variables in Equation (6) and the integration with the initial condition $\left(X=X_{o}\right.$ at $\left.t=t_{o}\right)$, it is possible to obtain Equation (5) [24]:

$$
\mu=\frac{\ln \left(\frac{\mathrm{x}}{\mathrm{x}_{0}}\right)}{\mathrm{t}-\mathrm{t}_{0}},
$$

where $t_{0}$ is the initial time of the exponential growth phase and $X_{0}$ is the corresponding biomass concentration.

Unsegregated and unstructured kinetic models were proposed to express the specific growth rate as a function of the limiting substrate concentration, as in the Monod model [21] in Equation (6); the cell density, as in the logistic model [25] in Equation (7); and both the cell and substrate concentrations, as in the Contois model [26] in Equation (8).

$$
\mu(S)=\mu_{\max } \frac{S}{S+K_{s}},
$$




$$
\begin{aligned}
& \mu(X)=\mu_{\max }\left(1-\frac{X}{X_{m}}\right), \\
& \mu(X, S)=\mu_{\max } \frac{S}{S+K_{S} X^{\prime}}
\end{aligned}
$$

where $\mu_{\max }, \mathrm{S}, \mathrm{K}_{\mathrm{s}}, \mathrm{X}$, and $\mathrm{X}_{\mathrm{m}}$ are the maximum specific growth rate $\left(\mathrm{h}^{-1}\right)$, limiting substrate concentration $(\mathrm{g} / \mathrm{L})$, semi-saturation constant $(\mathrm{g} / \mathrm{L})$, biomass concentration $(\mathrm{g} / \mathrm{L})$, and maximum biomass concentration $(\mathrm{g} / \mathrm{L})$, respectively. In the Contois model, $\mathrm{K}_{\mathrm{s}}(\mathrm{g} / \mathrm{g})$ is the substrate to biomass ratio corresponding to half of the maximum specific growth rate.

The lactic acid production rate, $r_{p}$, was expressed by the Luedeking-Piret model $[27,28]$, as shown in Equation (9):

$$
\mathrm{r}_{\mathrm{p}}=\frac{\mathrm{dP}}{\mathrm{dt}}=\alpha \frac{\mathrm{dX}}{\mathrm{dt}}+\beta \mathrm{X},
$$

where $\mathrm{P}(\mathrm{g} / \mathrm{L})$ is the lactic acid concentration and $\alpha(\mathrm{g} / \mathrm{g})$ and $\beta(\mathrm{g} / \mathrm{g} h)$ are the growthlinked and non-growth-linked constants.

\subsection{Statistical Analysis}

Statistical analysis was performed using Microsoft Excel $2016^{\circledR}$. Fermentation tests, lactic acid, starch, and glucose analyses were carried out in triplicate and, for each set of experimental data, mean values and standard deviations $(n=3)$ were calculated. Their statistical significance was evaluated by the Student's $t$-test, accepting only results with $p<0.05$ as significant.

Microsoft Excel 2016 ${ }^{\circledR}$ Solver ${ }^{\circledR}$ was used to estimate the kinetic constants of each model, solving non-linear regressions by the non-linear generalized reduced gradient (GRG) method.

The solver provides the values for the kinetic parameters that minimize the objective function, the residual sum of squares (RSS), calculated as the sum of squared differences between experimental and theoretical data obtained for the specific growth rate, as in Equation (10).

$$
\text { RSS }=\sum_{\mathrm{i}}\left(\mu_{\text {experimental }}-\mu_{\text {theoretical }}\right)^{2},
$$

where $\mu_{\text {experimental }}$ and $\mu_{\text {theoretical }}$ are the specific growth rates calculated from the experimental data and the mathematical models, respectively.

\section{Results and Discussions}

\subsection{Enzymatic Treatment and Fermentation Results}

The glucose and starch content in the raw rice flour (RRF), the un-pretreated rice flour suspension (URFS), and the hydrolyzed rice flour suspension (HRFS) before the fermentation process are reported in Table 1 . The glucose value for HRFS includes the glucose initially present in the raw rice flour $\left(0.45 \pm 0.04 \mathrm{mg} / \mathrm{g}_{\text {flour }}\right)$, added glucose $\left(66.67 \pm 0.04 \mathrm{mg} / \mathrm{g}_{\text {flour }}\right)$, and glucose resulting from the enzymatic hydrolysis of starch using amylase $\left(28.28 \pm 0.24 \mathrm{mg} / \mathrm{g}_{\text {flour }}\right)$. It is possible to observe a hydrolyzed starch percentage of $82.68 \pm 0.07 \%$ and glucose release of $3.67 \pm 0.01 \%$, evaluated with respect to the total starch content.

Table 1. Starch and glucose content in raw rice flour (RRF), un-pretreated rice flour suspension (URFS), and hydrolyzed rice flour suspension (HRFS); $\Delta_{\text {hydrolysis }}$ of starch and glucose resulting from the enzymatic treatment as percent variation and evaluated with respect to the initial starch amount. The values marked with different lowercase letters in the same arrow are significantly different $(p<0.05)$.

\begin{tabular}{lcccc}
\hline & $\begin{array}{c}\text { RRF } \\
\left(\mathbf{m g} / \mathbf{g}_{\text {flour }}\right)\end{array}$ & $\begin{array}{c}\text { URFS } \\
\left(\mathbf{m g} / \mathbf{g}_{\text {flour }}\right)\end{array}$ & $\begin{array}{c}\text { HRFS } \\
\left(\mathbf{m g} / \mathbf{g}_{\text {flour }}\right)\end{array}$ & $\begin{array}{c}\left|\Delta_{\text {hydrolysis }}\right| \\
\mathbf{( \% )}\end{array}$ \\
\hline Starch & $770 \pm 4.20^{\mathrm{a}}$ & $770 \pm 4.20^{\mathrm{a}}$ & $133.33 \pm 18.98^{\mathrm{b}}$ & $82.68 \pm 0.07$ \\
Glucose & $0.45 \pm 0.04^{\mathrm{a}}$ & $67.11 \pm 0.04^{\mathrm{b}}$ & $95.40 \pm 0.16^{\mathrm{c}}$ & $3.67 \pm 0.01$ \\
\hline
\end{tabular}


In Gallo et al. [29], enzymatic pretreatment of a $52 \% w / v$ wheat flour aqueous suspension was carried out using amylase $(0.017 \% w / v)$ at $59{ }^{\circ} \mathrm{C}$ for $30 \mathrm{~min}$. In that case, a hydrolyzed starch percentage of $81.41 \%$, similar to that obtained in this work, was achieved.

The fermentation results shown in Figure 1 have already been discussed by Gallo et al. [11], where the effect of $\mathrm{pH}$ control on bacterial growth and lactic acid production during rice fermentation using LP CBA L74 was investigated.
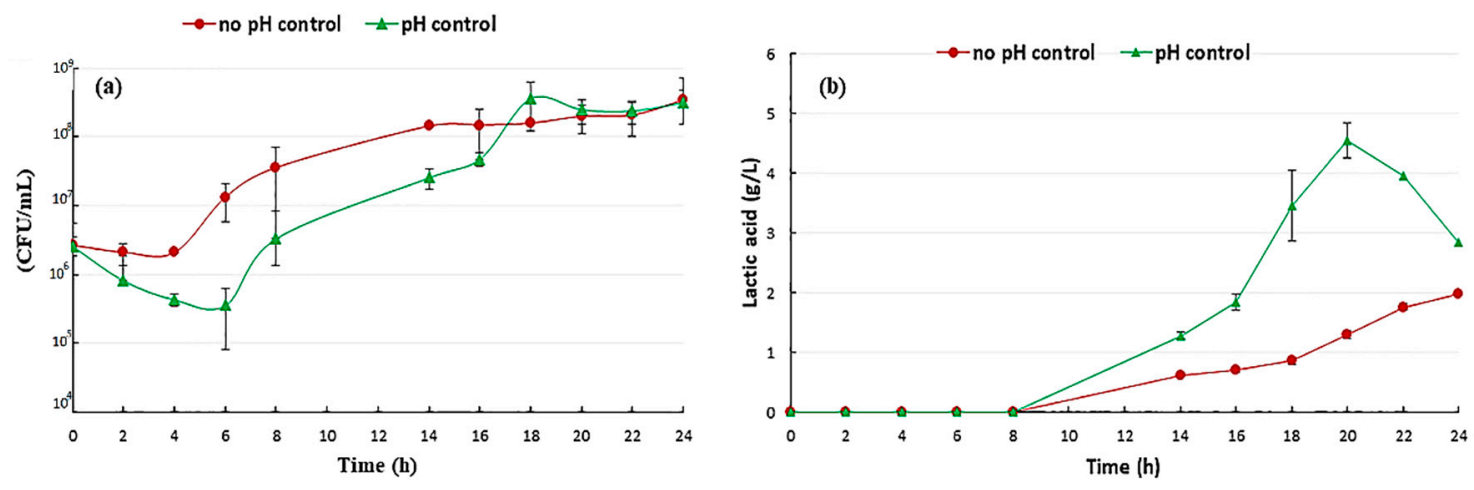

Figure 1. Bacterial growth (a) and lactic acid production (b) curves during rice flour fermentation carried out with and without pH control. Data were taken from Gallo et al. [11].

In Figure 2, the glucose consumption during the fermentation process, carried out with and without $\mathrm{pH}$ control, was reported. The Student's $t$-test found significant differences between the glucose consumption curves obtained during the fermentation process with and without $\mathrm{pH}$ control $(p<0.05)$, except for the glucose concentration values determined at $\mathrm{t}_{18}$ and $\mathrm{t}_{20}(p>0.05)$.

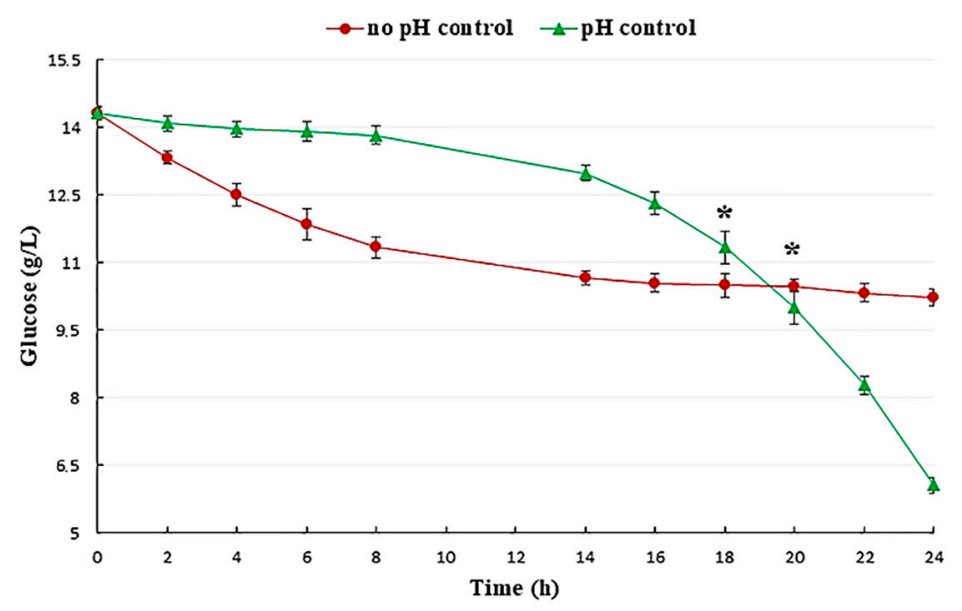

Figure 2. Glucose concentration during the fermentation process. (Student's $t$-test provided $p<0.05$ for all points, except for the glucose values at 18 and $20 \mathrm{~h}$, marked with asterisks, ${ }^{*}$ ).

When $\mathrm{pH}$ control was applied, the glucose concentration was almost constant during the cell lag phase (from $t_{0}$ to $t_{4}$ ), decreasing with a lower consumption rate until the end of exponential phase (from $t_{4}$ to $t_{14}$ ) and becoming more pronounced toward the end of the process (from $t_{14}$ to $t_{24}$ ), with an overall decrease in glucose content in the fermenting medium of $28.56 \% \pm 1.88 \%$. The simultaneous decrease in lactic acid concentration during the last hours of the process could be associated with the high concentration of sodium hydroxide added to rice suspension for controlling $\mathrm{pH}$. The high ionic strength of the suspension could affect the lactate solubility and lead to its precipitation, resulting in a lower lactic acid amount observed in the fermenting medium from $t_{20}$ to $t_{24}$. 
By contrast, when the fermentation process was performed without control of $\mathrm{pH}$, the glucose concentration showed a fast decrease from the early stages of the process (from $t_{0}$ to $_{6}$ ) and during the exponential growth phase (from $t_{6}$ to $t_{18}$ ), remaining almost constant during the stationary growth phase. The total glucose consumption during the fermentation with $\mathrm{pH}$ control was $57.62 \% \pm 1.52 \%$. Moreover, in both conditions, the starch concentration remained constant at a value of $20 \mathrm{~g} / \mathrm{L}$ during the process, indicating that the glucose amount in the hydrolyzed rice suspension can be considered sufficient to satisfy the nutritional requirements of the microorganism.

\subsection{Fermentation Parameters}

The doubling time of the microorganism $t_{d}$, the number of generations $n$, and the constant growth rate $\mathrm{k}$, evaluated during the exponential growth phase of fermentation with and without $\mathrm{pH}$ control, are reported in Table 2.

Table 2. Fermentation parameters evaluated during the exponential growth phase of fermentation with and without $\mathrm{pH}$ control: doubling time $\left(\mathrm{t}_{\mathrm{d}}\right)$; constant growth rate $(\mathrm{k})$; generation number $(\mathrm{n})$.

\begin{tabular}{cccc}
\hline Process Conditions & $\mathbf{t}_{\mathbf{d}}(\mathbf{h})$ & $\mathbf{k}\left(\mathbf{h}^{-\mathbf{1}}\right)$ & $\mathbf{n}$ \\
\hline Without $\mathrm{pH}$ control & 1.52 & 0.66 & 6.58 \\
With $\mathrm{pH}$ control & 1.21 & 0.83 & 9.92 \\
\hline
\end{tabular}

As shown in Table 2, when $\mathrm{pH}$ control was performed, fermentation tests provided higher values of the generation number, $\mathrm{n}$, and the constant growth rate, $\mathrm{k}$ (9.92 and $0.83 \mathrm{~h}^{-1}$, respectively) and, thus, a lower doubling time $\mathrm{t}_{\mathrm{d}}$ of $1.21 \mathrm{~h}$ in comparison with the values of $6.58,0.66 \mathrm{~h}^{-1}$, and $1.52 \mathrm{~h}$, calculated for $\mathrm{n}, \mathrm{k}$, and $\mathrm{t}_{\mathrm{d}}$, respectively, in the absence of $\mathrm{pH}$ control.

These results indicate the better duplication capacity of the microorganism during the exponential growth phase, when the $\mathrm{pH}$ of the rice medium is controlled at the optimal value for the microorganism's growth throughout the entire period of fermentation.

According to Colucci Cante et al. [8], a higher doubling time of $2.21 \mathrm{~h}$ was determined for LP CBA L74 during the fermentation of a cooked bean suspension without $\mathrm{pH}$ control.

Moreover, the $\mathrm{pH}$ control allowed us to achieve comparable doubling time values to those obtained by Soro-Yao et al. [30] during the fermentation of MRS broth using Lactobacillus plantarum and Lactococcus spp. (1.33 and $1.22 \mathrm{~h}$, respectively).

\subsection{Kinetic Constants}

In Table 3, the kinetic constants $\mu_{\max }, \mathrm{K}_{\mathrm{s}}$, and $\mathrm{X}_{\mathrm{m}}$ of the Monod, Logistic, and Contois models are reported.

Without $\mathrm{pH}$ control, the specific experimental growth rate was more appropriately described by the Contois model $\left(R^{2}=0.990\right)$. The specific growth rate decrease was not only linked to the glucose consumption, as expressed by the Monod model $\left(R^{2}=0.742\right)$, or to the biomass increase in the fermenting medium, as assumed in the Logistic model $\left(R^{2}=0.874\right)$, but both contributions could also be considered relevant for describing the microbial growth kinetics. The maximum specific growth rate $\mu_{\max }$ and the semi-saturation constant $\mathrm{K}_{\mathrm{s}}$ calculated by the Contois model were $0.993 \mathrm{~h}^{-1}$ and $124.961 \mathrm{~g} / \mathrm{g}$, respectively, indicating that only during the first stages of the exponential phase, when the glucose to biomass concentration S/X ratio was higher or of the same order of magnitude than the constant $\mathrm{K}_{\mathrm{s}}$, the specific growth rate was approximately higher or equal to half of the maximum growth rate (Figure 3 ).

Subsequently, the growth rate dropped to lower values as it became more influenced by both the biomass increase and the substrate decrease that occur during the fermentation process. 
When the fermentation process was carried out with $\mathrm{pH}$ control, both the Monod and Contois models satisfactorily described the specific growth rate trend, with $\mathrm{R}^{2}$ values of 0.987 and 0.985 , respectively.

Table 3. The growth kinetic constants of Monod, logistic, and Contois models ( $\mu_{\max }$ : maximum specific growth rate; $\mathrm{K}_{\mathrm{s}}$ : semi-saturation constant; $X_{m}$ : maximum biomass concentration), the residual sum of squares RSS, and the correlation coefficient $\mathrm{R}^{2}$, calculated for fermentations with and without $\mathrm{pH}$ control.

\begin{tabular}{|c|c|c|c|c|c|c|c|c|c|c|c|c|}
\hline & \multicolumn{4}{|c|}{ Monod } & \multicolumn{4}{|c|}{ Contois } & \multicolumn{4}{|c|}{ Logistic } \\
\hline & $\begin{array}{l}\mu_{\max } \\
\left(h^{-1}\right)\end{array}$ & $\begin{array}{c}K_{s} \\
(g / L)\end{array}$ & RSS & $\mathbf{R}^{2}$ & $\begin{array}{l}\mu_{\max } \\
\left(h^{-1}\right)\end{array}$ & $\begin{array}{c}K_{s} \\
(g / g)\end{array}$ & RSS & $\mathbf{R}^{2}$ & $\begin{array}{l}\mu_{\max } \\
\left(h^{-1}\right)\end{array}$ & $\begin{array}{c}X_{m} \\
(g / L)\end{array}$ & RSS & $\mathbf{R}^{2}$ \\
\hline $\begin{array}{l}\text { No pH } \\
\text { control }\end{array}$ & 0.811 & 10.124 & 0.1101 & 0.742 & 0.993 & 124.961 & 0.0041 & 0.990 & 0.619 & 0.437 & 0.0537 & 0.874 \\
\hline $\mathrm{pH}$ control & 0.734 & 4.880 & 0.0061 & 0.987 & 0.517 & 0.001 & 0.0071 & 0.985 & 0.472 & 28.665 & 0.0338 & 0.928 \\
\hline
\end{tabular}

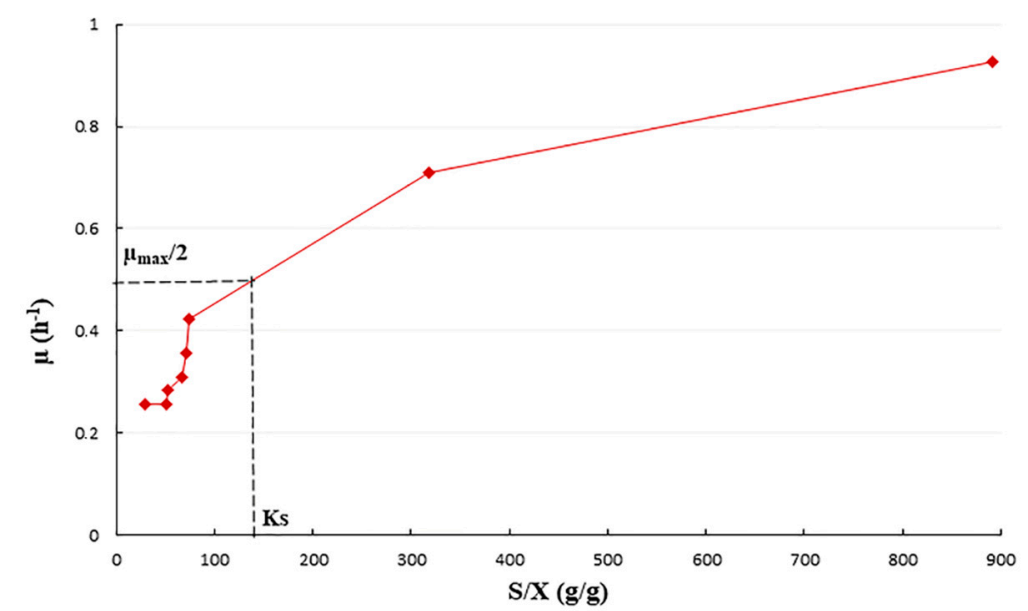

Figure 3. Specific growth rate $\mu$ as function of glucose to biomass concentration $S / X$ ratio during fermentation without $\mathrm{pH}$ control. Dashed lines indicate the values calculated for $\mu_{\max }$ and Ks by the Contois model.

The Monod model provided $\mu_{\max }$ and $\mathrm{K}_{\mathrm{s}}$ values of $0.734 \mathrm{~h}^{-1}$ and $4.880 \mathrm{~g} / \mathrm{L}$, respectively, indicating that the glucose concentration in the fermenting medium always ensured a higher specific growth rate than half of its maximum value and satisfied the nutritional requirement of the microorganism, as shown in Figure $4 \mathrm{a}$. In Figure $4 \mathrm{~b}$, the specific growth rate as a function of the ratio of $S / X$ is reported. The ratio of $S / X$ was always higher than the constant Ks value determined for the Contois model, ensuring a high specific growth rate during the entire process, without any limitations provided by the decreasing glucose content and/or the increasing biomass concentration.

Moreover, the logistic model provided a high value for the maximum biomass concentration $X_{m}=28.665 \mathrm{~g} / \mathrm{L}$, confirming that the biomass density in the fermenting suspension never limited the cell growth rate.

In Ardestani et al. [24] and Rezvani et al. [17], the growth rate of five Lactobacilli (Lactobacillus casei, Lactobacillus delbrueckii, Lactobacillus bulgaricus, Lactobacillus fermentum, and Lactobacillus lactis) in a batch submerged culture of whey with added lactose was modelled using Monod, Logistic, and Contois models, respectively. As well as for LP CBA L74 used in this work without $\mathrm{pH}$ control, Contois resulted to fit the experimental data obtained using Lactobacillus bulgaricus with higher accuracy $\left(\mathrm{R}^{2}=0.95\right)$ than that resulting from the Monod and Logistic models $\left(R^{2}=0.890\right.$ and $R^{2}=0.897$, respectively) [17]. Moreover, both Monod and Contois models provided an acceptable fitting of the growth rate when Lactobacillus casei was used during the fermentation process $\left(\mathrm{R}^{2}=0.965\right.$ and $R^{2}=0.955$, respectively) while a lower accuracy $\left(R^{2}=0.892\right)$ was observed when the Logistic equation was applied $[17,24]$. 

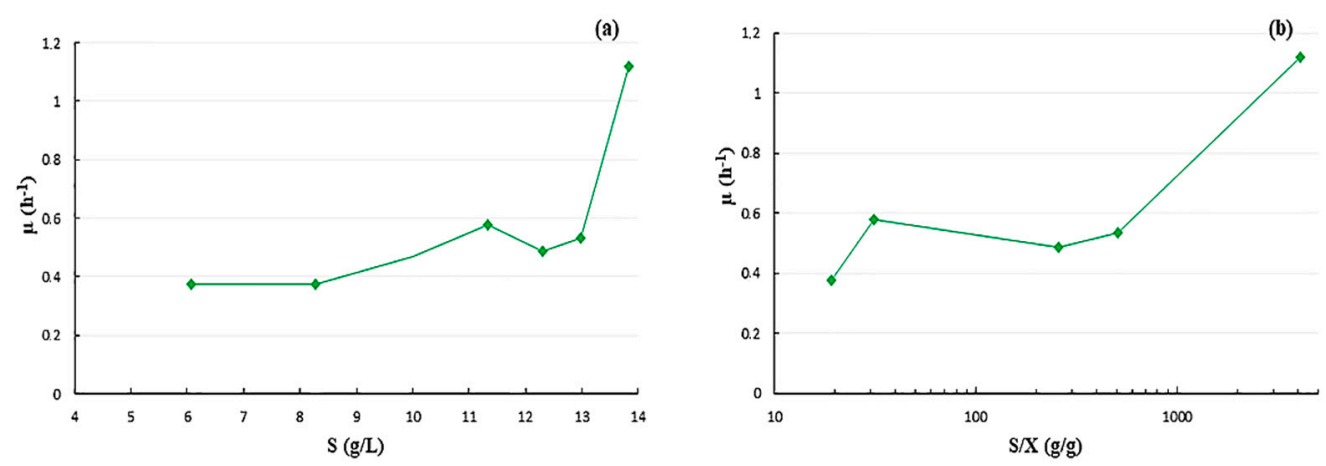

Figure 4. Specific growth rate $\mu$ as function of the glucose concentration $S$ (a) and the glucose to biomass weight $S / X$ ratio, expressed in logarithmic scale (b) during the fermentation process performed with $\mathrm{pH}$ control.

The results obtained could also justify the initial glucose addition to the rice suspension in view of the kinetic improvement of the process. In this work, the kinetic results indeed demonstrate that $1 \%$ glucose addition is still not sufficient to guarantee a suitable specific growth rate when $\mathrm{pH}$ is not controlled, but it can be considered adequate to satisfy the nutritional requirements of the microorganism when $\mathrm{pH}$ control is performed during the process.

In Table 4 , the kinetic constants $\alpha$ and $\beta$ for the lactic acid production rate, determined by the Luedeking-Piret model, are reported.

Table 4. The kinetic constants of the Luedeking-Piret model ( $\alpha$ : growth-linked constant; $\beta$ : nongrowth-linked constant), RSS, and the correlation coefficient $\mathrm{R}^{2}$, calculated for fermentations with and without $\mathrm{pH}$ control.

\begin{tabular}{cccccc}
\hline & $\alpha(\mathbf{g} / \mathbf{g})$ & $\boldsymbol{\beta}(\mathbf{g} / \mathbf{g}$ h) & $|\boldsymbol{\alpha} / \boldsymbol{\beta}|$ & $\mathbf{R S S}$ & $\mathbf{R}^{2}$ \\
\hline Without pH control & 0.001 & 0.489 & 0.002 & 0.0013 & 0.958 \\
With pH control & 19.539 & -8.637 & 2.262 & 0.3305 & 0.762 \\
\hline
\end{tabular}

For fermentations without $\mathrm{pH}$ control, constants $\alpha$ and $\beta$ were $0.001 \mathrm{~g} / \mathrm{g}$ and $0.489 \mathrm{~g} / \mathrm{g}$, respectively. As expected, the lactic acid production rate was mainly non-growth linked, with an $\alpha / \beta$ ratio of 0.002 . In fact, lactic acid started to increase after $8 \mathrm{~h}$ of process, reaching its maximum concentration during the stationary phase $\left(1.987 \mathrm{~g} / \mathrm{L}\right.$, at time $\left.\mathrm{t}_{24}\right)$.

Conversely, Alvarez et al. [14] and Thakur et al. [31] reported lactic acid production rates that were mainly associated with biomass growth, during a lactic acid fermentation process for milk whey using Lactobacillus casei var. rhamnosus $(\alpha / \beta=9.47)$ and sugarcane molasses with Lactobacillus casei MTCC $1423(\alpha / \beta=2.79)$, respectively.

When $\mathrm{pH}$ control was applied, the Luedeking-Piret model fit the experimental lactic acid production rate with a low accuracy $\left(\mathrm{R}^{2}=0.762\right)$, providing an uncommon negative non-growth-linked constant $\beta(-8.637 \mathrm{~g} / \mathrm{g} \mathrm{h})$, which reproduced the decreasing tract of the lactic acid curve observed after $20 \mathrm{~h}$ of process.

Future purposes will be a more appropriate kinetic modeling of the lactic acid production and a further optimization of the fermentation protocol with $\mathrm{pH}$ control in terms of added glucose percentage, in view of a future scale up of the process.

\section{Conclusions}

The aim of the present work was to perform a kinetic analysis of the results reported by Gallo et al. [11] for rice flour fermentation performed using Lactobacillus paracasei CBA L74 with and without $\mathrm{pH}$ control. Gallo et al. [11] had already demonstrated the possibility of improving the functional properties of the fermented rice product by controlling $\mathrm{pH}$ at 5.8 , but a comparison between the kinetic performances, corresponding to the two different process conditions, had not been conducted yet. When $\mathrm{pH}$ control was performed, the microorganism showed a better duplication capacity during the exponential growth phase, 
providing higher values of the generation number $\mathrm{n}$ and the constant growth rate $\mathrm{k}(9.92$ and $0.83 \mathrm{~h}^{-1}$, respectively) and a lower doubling time $\mathrm{t}_{\mathrm{d}}$ of $1.21 \mathrm{~h}$ in comparison with the values obtained in the absence of $\mathrm{pH}$ control.

Three kinetic models were proposed to describe the bacterial growth rate in both conditions: the Monod, Logistic, and Contois models. When fermentation was carried out without $\mathrm{pH}$ control, the best mathematical model able to describe the experimental data was the Contois model, showing that the specific growth rate was affected both by the glucose reduction and the biomass production that occurred during the fermentation process. When $\mathrm{pH}$ control was applied, both Monod and Contois models satisfactorily described the specific growth rate trend.

Therefore, the constants Ks and $\mu_{\max }$ confirmed that the glucose content in the fermenting suspension satisfied the nutritional requirements of microorganisms and that the growth kinetic was not affected by the decreasing glucose content and/or the increasing biomass concentration.

Moreover, the Luedeking-Piret model was applied for modeling the lactic acid production rate, which appeared mainly non-growth linked, as confirmed by the $\alpha / \beta$ ratio of 0.002 , calculated in the absence of $\mathrm{pH}$ control. The Luedeking-Piret model was not appropriate for describing the experimental lactic acid rate when $\mathrm{pH}$ was controlled.

In conclusion, the kinetic study reported in this work allowed us to validate the results discussed by Gallo et al. [11], showing the convenience of controlling $\mathrm{pH}$ during the rice flour fermentation process with LP CBA L74 and also in terms of the microbial growth rate. Therefore, optimal growth conditions in terms of the $\mathrm{pH}$ value of the fermenting medium allowed the microorganism to also improve its fermentation performance from a kinetic point of view, providing high specific growth rates that were not significantly influenced by the increasing biomass amount or the substrate consumption in the fermenting medium.

Author Contributions: Conceptualization, R.C.C., M.G., F.P. and R.N.; methodology, R.C.C., M.G., F.N., F.P. and R.N.; validation, R.C.C., M.G. and R.N.; Resources, A.B.; formal analysis, R.C.C., M.G., F.N. and F.P.; data curation, R.C.C., F.N. and F.P.; writing-original draft, R.C.C.; writing-review and editing, R.C.C.; supervision, M.G. and R.N.; project administration, M.G. and R.N. All authors have read and agreed to the published version of the manuscript.

Funding: This research did not receive any specific grants from funding agencies in the public, commercial, or not-for-profit sectors.

Institutional Review Board Statement: Not applicable.

Informed Consent Statement: Not applicable.

Data Availability Statement: Not applicable.

Conflicts of Interest: The authors declare no conflict of interest. Andrea Budelli is currently employed by Heinz BV, Netherlands. He provided the raw materials and Lactobacillus paracasei CBA L74. Heinz BV did not provide any financial support to the authors for the experimental activity, and did not have any additional role in the study design, data collection and analysis, decision to publish, or preparation of the manuscript.

\section{References}

1. Menrad, K. Market and marketing of functional food in Europe. J. Food Eng. 2003, 56, 181-188. [CrossRef]

2. Gomes, A.M.P.; Malcata, X.F. Bifidobacterium ssp. and Lactobacillus acidophilus: Biological, biochemical, technological and therapeutical properties relevant for use as probiotics. Trends Food Sci. Technol. 1999, 10, 139-157. [CrossRef]

3. Prado, F.C.; Parada, J.L.; Pandey, A.; Soccol, C. Trends in non-dairy probiotic beverages. Food Res. Int. 2008, 41, 111-123. [CrossRef]

4. Nocerino, R.; Paparo, L.; Terrin, G.; Pezzella, V.; Amoroso, A.; Cosenza, L.; Cecere, G.; De Marco, G.; Micillo, M.; Albano, F.; et al. Cow's milk and rice fermented with Lactobacillus Paracasei CBA L74 prevent infectious diseases in children: A randomized controlled trial. Clin. Nutr. 2017, 36, 118-125. [CrossRef] [PubMed]

5. Gallo, M.; Nigro, F.; Passannanti, F.; Salameh, D.; Schiattarella, P.; Budelli, A.; Nigro, R. Lactic fermentation of Cereal Flour: Feasibility tests on rice, oat and wheat. Appl. Food Biotechnol. 2019, 6, 165-172. [CrossRef] 
6. Gallo, M.; Passannanti, F.; Colucci Cante, R.; Nigro, F.; Salameh, D.; Schiattarella, P.; Schioppa, C.; Budelli, A.; Nigro, R. Effects of the glucose addition during lactic fermentation of rice, oat and wheat flours. Appl. Food Biotechnol. 2020, 7, 21-30.

7. Gallo, M.; Passannanti, F.; Colucci Cante, R.; Nigro, F.; Schiattarella, P.; Zappulla, S.; Budelli, A.; Nigro, R. Lactic fermentation of cereals aqueous mixture of oat and rice flours with and without glucose addition. Heliyon 2020, 6, e04920. [CrossRef] [PubMed]

8. Colucci Cante, R.; Gallo, M.; Nigro, F.; Passannanti, F.; Salameh, D.; Budelli, A.; Nigro, R. Lactic fermentation of cooked navy beans by Lactobacillus paracasei CBA L74 aimed at a potential production of functional legume-based foods. Can. J. Chem. Eng. 2020, 98, 1955-1961. [CrossRef]

9. Salameh, D.; Nigro, F.; Colucci Cante, R.; Passannanti, F.; Gallo, M.; Budelli, A.; Marzocchella, A.; Nigro, R. Fermentation of rice flour supernatant using Lactobacillus Paracasei CBA L74. Chem. Eng. Trans. 2019, 75, 289-294. [CrossRef]

10. Sarno, M.; Lania, G.; Cuomo, M.; Nigro, F.; Passannanti, F.; Budelli, A.; Fasano, F.; Troncone, R.; Auricchio, S.; Barone, M.V.; et al. Lactobacillus paracasei CBA L74 interferes with gliadin peptides entrance in Caco-2 cells. Int. J. Food Sci. Nutr. 2014, 65, 953-959. [CrossRef]

11. Gallo, M.; Nigro, F.; Passannanti, F.; Nanayakkara, M.; Lania, G.; Parisi, F.; Salameh, D.; Budelli, A.; Barone, M.V.; Nigro, R. Effect of $\mathrm{pH}$ control during rice fermentation in preventing a gliadin P31-43 entrance in epithelial cells. Int. J. Food Sci. Nutr. 2019, 70, 950-958. [CrossRef]

12. Linville, J.L.; Rodriguez Jr, M.; Mielenz, J.R.; Cox, C.D. Kinetic modelling of batch fermentation for Populus hydrolysate tolerant mutant and wild type strains of Clostridium thermocellum. Bioresour. Technol. 2013, 147, 605-613. [CrossRef]

13. Gupta, S.; Abu-Ghannam, N.; Scannell, A. Growth and kinetics of Lactobacillus plantarum in the fermentation of edible Irish brown seaweeds. Food Bioprod. Process. 2011, 89, 346-355. [CrossRef]

14. Alvarez, M.M.; Aguirre-Ezkauriatza, E.J.; Ramírez-Medrano, A.; Rodríguez-Sánchez, Á. Kinetic analysis and mathematical modelling of growth and lactic acid production of Lactobacillus casei var. rhamnosus in milk whey. J. Dairy Sci. 2010, 93, 5552-5560. [CrossRef]

15. Del Nobile, M.A.; Altieri, C.; Corbo, M.R.; Sinigaglia, M.; La Notte, E. Development of a structured model for batch cultures of lactic acid bacteria. J. Ind. Microbiol. Biotechnol. 2003, 30, 421-426. [CrossRef]

16. Gadgil, C.J.; Venkatesh, K.V. Structured model for batch culture growth of Lactobacillus bulgaricus. J. Chem. Technol. Biotechnol. 1996, 68, 89-93. [CrossRef]

17. Rezvani, F.; Ardestani, F.; Najafpour, G. Growth kinetic models of five species of Lactobacilli and lactose consumption in batch submerged culture. Braz. J Microbiol. 2017, 48, 251-258. [CrossRef] [PubMed]

18. Schepersa, A.W.; Thibault, J.; Lacroix, C. Lactobacillus helveticus growth and lactic acid production during $\mathrm{pH}$-controlled batch cultures in whey permeate/yeast extract medium. Part II: Kinetic modelling and model validation. Enzyme Microb. Technol. 2002, 30, 187-194. [CrossRef]

19. Venkatesh, K.V.; Okos, M.R.; Wankat, P.C. Kinetic model of growth and lactic acid production from lactose by Lactobacillus bulgaricus. Process Biochem. 1993, 28, 231-241. [CrossRef]

20. Nielsen, J.; Nikolajsen, K.; Villadsen, J. Structured modelling of a microbial system: I. A theoretical study of lactic acid fermentation. Biotechnol. Bioeng. 1991, 38, 1-10. [CrossRef] [PubMed]

21. Monod, J. The growth of bacterial cultures. Annu. Rev. Microbiol. 1949, 3, 371-394. [CrossRef]

22. Muloiwaa, M.; Nyende-Byakikab, S.; Dinkab, M. Comparison of unstructured kinetic bacterial growth models. S. Afr. J. Chem. Eng. 2020, 33, 141-150. [CrossRef]

23. Maier, M.R. Bacterial growth. In Environmental Microbiology, 2nd ed.; Maier, M.R., Pepper, I.L., Gerba, C.P., Eds.; Academic Press: Cambridge, MA, USA, 2009; pp. 37-54. [CrossRef]

24. Ardestani, F.; Rezvani, F; Najafpour, G. Evaluation of cell growth and substrate consumption kinetic of five different Lactobacilli in a submerged batch whey culture for lactic acid production. Int. J. Eng. Sci. 2015, 28, 970-977.

25. Ricker, W.E. Growth rates and models. In Fish Physiology, Bioenergetics and Growth, 3rd ed.; Hoar, W.S., Randall, D.J., Brett, J.R., Eds.; Academic Press: New York, NY, USA, 1979; Volume 8, pp. 677-743.

26. Contois, D.E. Kinetics of bacterial growth: Relationship between population density and specific growth rate of continuous cultures. J. Gen. Microbiol. 1959, 21, 40-50. [CrossRef]

27. Luedeking, R.; Piret, E.L. A kinetic study of the lactic acid fermentation. Batch process at controlled pH. J. Biochem. Microbiol. Technol. Eng. 1959, 1, 393-412. [CrossRef]

28. Luedeking, R.; Piret, E.L. Transient and steady states in continuous fermentation: Theory and experiments. J. Biochem. Microbiol. Technol. Eng. 1959, 1, 431-459. [CrossRef]

29. Gallo, M.; Passannanti, F.; Schioppa, C.; Montella, S.; Colucci Cante, R.; Nigro, F.; Budelli, A.; Nigro, R. Enzymatic pre-treatment and lactic fermentation of wheat flour suspension at high solid content. J. Food Process. Preserv. 2020, e15299. [CrossRef]

30. Soro-Yao, A.A.; Aka, S.; Thonart, P.; Djè, K.D. Assessment of the potential of lactic acid bacteria as dried starter culture for cereal fermentation. Open Biotechnol. J. 2014, 8, 1-5. [CrossRef]

31. Thakur, A.; Panesar, P.S.; Saini, M.S. Optimization of process parameters and estimation of kinetic parameters for lactic acid production by Lactobacillus casei MTCC 1423. Biomass Conv. Bioref. 2019, 9, 253-266. [CrossRef] 